\title{
Acute clouding of a trifocal intraocular lens with spontaneous resolution: a case report
}

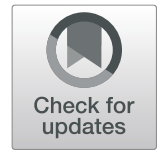

Tao Zhang ${ }^{1,2}$, Shaowei Li ${ }^{1,3^{*}}$, Chang Liư ${ }^{3}$, Ruihua Zhao ${ }^{3}$, Chenghe $\mathrm{Chang}^{3}$ and $\mathrm{Na} \mathrm{Han}^{3}$

\begin{abstract}
Background: Opacification of hydrophobic and hydrophilic intraocular lenses (IOLs) has been reported. Herein, we report a case of spontaneous resolution of opacification following acute clouding of a trifocal IOL, which consisted of hydrophilic acrylic material (25\%) with hydrophobic surface properties, occurring in a cold region in the winter season.

Case presentation: A young adult with bilateral radiation cataract underwent phacoemulsification using a femtosecond laser and implantation of a trifocal IOL. The trifocal IOL was delivered to the operating theatre $30 \mathrm{~min}$ before the surgery. The outside temperature was approximately $-7^{\circ} \mathrm{C}$. The IOL package was warmed using a radiator at approximately $35^{\circ} \mathrm{C}$ for $15 \mathrm{~min}$. After the optical region was implanted in the eye, cloudiness was observed, which persisted throughout the operation. Complete clearing of the IOL was apparent after three postoperative hours.

Conclusion: In this case, rapid opacification and clearing of the IOL suggested an acute and transient process. IOLs should be stored and shipped at a constant temperature, and sudden temperature fluctuations should be avoided, especially in the colder seasons.
\end{abstract}

Keywords: AT LISA tri 839MP, Clouding, Clearing

\section{Background}

Trifocal intraocular lenses (IOLs) provide visual acuity similar to the normal visual acuity of the human eye. However, IOL opacification is a severe complication of cataract surgery, resulting in blurred vision and explantation of both hydrophilic and hydrophobic IOLs [1-3]. Delayed IOL opacification is known as "pseudocataract" [4]. Intraoperative acute clouding of acrylic hydrophilic IOLs with spontaneous resolution has been reported [5]. Herein, we report a case of early intraoperative opacification of a trifocal IOL (AT LISA tri 839MP, Carl Zeiss Meditec, Jena, Germany) with resolution within three postoperative hours.

\footnotetext{
*Correspondence: shaoweili2006@163.com

'Department of Ophthalmology, Aier School of Ophthalmology, Central South University, 932 South LushanYuelu District, Changsha 410083, People's Republic of China

${ }^{3}$ Department of Ophthalmology, Beijing Aier-Intech Eye Hospital, NO.12 Panjiayuan NanliChaoyang District, Beijing 100021, People's Republic of China

Full list of author information is available at the end of the article
}

\section{Case presentation}

A 25-year-old man presented with bilateral cataract. He underwent cataract surgery in the right eye with a femtosecond laser to correct astigmatism and implantation of a +15.0-dioptre trifocal IOL (AT LISA tri 839MP, Carl Zeiss). The operation was performed by the author Dr. Li on January 16, 2018.

Drugs were administered perioperatively following the standard protocol. Docking of the patient's eye was performed; femtosecond laser instruments were used to perform anterior capsulorhexis and sequential nuclear division; a corneoscleral incision was made with a knife to strengthen the coalescence. Subsequently, phacoemulsification was performed uneventfully under a microscope.

Because of delay in shipping of the IOL package from another city, the IOL was delivered to the operating theatre only $30 \mathrm{~min}$ before the start of the operation. The outside temperature was approximately $-7^{\circ} \mathrm{C}$; therefore, the IOL package was warmed using a radiator at a temperature of approximately $35^{\circ} \mathrm{C}$ for $15 \mathrm{~min}$. Once the optical region was implanted in the eye, cloudiness was observed, which persisted throughout the operation.

(c) The Author(s). 2019 Open Access This article is distributed under the terms of the Creative Commons Attribution 4.0 International License (http://creativecommons.org/licenses/by/4.0/), which permits unrestricted use, distribution, and reproduction in any medium, provided you give appropriate credit to the original author(s) and the source, provide a link to the Creative Commons license, and indicate if changes were made. The Creative Commons Public Domain Dedication waiver (http://creativecommons.org/publicdomain/zero/1.0/) applies to the data made available in this article, unless otherwise stated. 
(Fig. 1a, b). Considering the possibility of spontaneous clearing, which was previously reported in an IOL of another brand and following consultation from an IOL specialist, the changes were monitored. Three hours postoperatively, the IOL became completely transparent, and the visual acuity was restored to 0.3 logarithm of the Minimal Angle of Resolution (Fig. 1c. At the scheduled follow-ups on postoperative days 1 and 3, no residual opacification or structural changes in the trifocal IOL (Fig. 1d) were observed, and the patient's uncorrected visual acuity was $20 / 20$.

\section{Discussion}

We reported a case of spontaneous resolution of trifocal IOL opacification following acute clouding. Although acute clouding of IOLs have been described by Liu et al. [6], both lenses in that study remained cloudy postoperatively for $1 \mathrm{~h}$ and $8 \mathrm{~min}$ in vivo, respectively. Therefore, a new IOL was implanted. However, the IOL in our case exhibited clearing within three postoperative hours.

After conducting photochemistry with the $400-420 \mathrm{~nm}$ wavelength of ultraviolet rays for 5 months, the patient suffered from bilateral radiation cataract. Toto et al. [7] reported that inflammatory infiltrates could be detected immunohistochemically in the anterior segment of both the eyes with cataract, induced with ultraviolet-B radiation exposure. However, there are no reports describing acute clouding associated with inflammation in bilateral radiation cataracts.
Pseudocataract could occur spontaneously because of calcium and phosphate accumulation, which results in hydroxyapatite crystal formation [8, 9]. Such delayed IOL opacification usually occurs after a few postoperative months [4], unlike our case. Tyagi et al. [1], Dhoot et al. [5], Liu et al. [6], and Helvaci et al. [10] reported that intraoperative clouding of hydrophilic and hydrophobic IOLs could be caused by sudden changes in temperature. In addition, the acute clouding reported by Tyagi et al. [1] lasted for approximately $3 \mathrm{~h}$ and disappeared spontaneously, and the opacification reported by Helvaci [10] resolved the following day. The opacification of two trifocal IOLs of the same company as ours reported by Liu et al. [8] persisted for $1 \mathrm{~h}$ and $8 \mathrm{~min}$, respectively, without any equilibration in vivo, and the second IOL became transparent $5 \mathrm{~min}$ later in vitro. Eventually, both IOLs were explanted, and an IOL of another brand (ZCB200, Allergan, Dublin, Ireland) was implanted. Severe fluctuations in temperature were also observed in the IOL in our case. However, acute clouding disappeared within three postoperative hours. Based on the aforementioned cases, the manufacturer's instructions state that the IOL should be at room temperature at the time of surgery to avoid temporary clouding of the lens optic following implantation. However, the time of resolution of the temporary clouding has not been elucidated, and there have been no reports of the spontaneous resolution of clouding of hybrid hydrophilic and hydrophobic IOLs. Considering that the package and
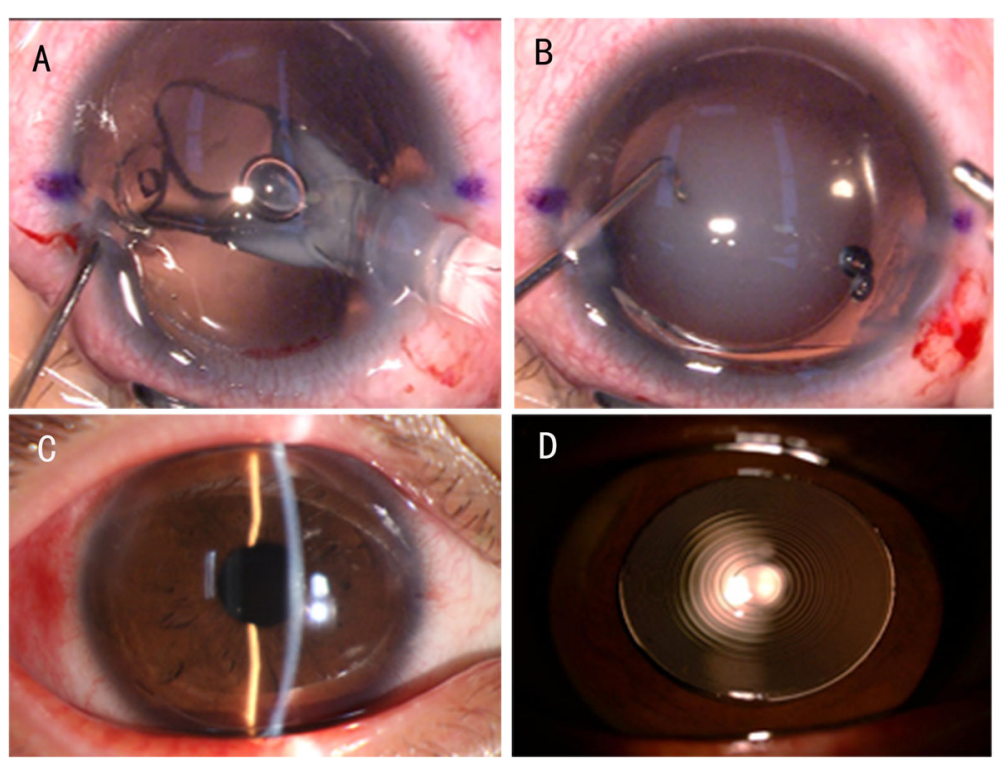

Fig. 1 a Clouding of the intraocular lens. Cloudiness was observed following implantation of the optical region in the eye. $\mathbf{b}$ Clouding of the intraocular lens. Cloudiness was observed following complete insertion of the intraocular lens in the anterior chamber of the eye and it persisted throughout the operation. $\mathbf{c}$ Intraocular lens at three postoperative hours. The intraocular lens was transparent, showing complete resolution of clouding, at three postoperative hours. $\mathbf{d}$ Intraocular lens on postoperative day 1. No residual opacification or structural changes are observed in the trifocal IOL on postoperative day 1 
storage buffer were intact, the acute IOL opacification could have resulted from sudden changes in temperature; therefore, we observed the condition and did not perform explantation. Regarding the formation of acute clouding, we hypothesized that the air inside the IOL was released when the temperature suddenly increased, resulting in microbubbles. Microbubbles and light refraction led to the appearance of clouding. When air dissolution reached an equilibrium both in water and the IOL, the clouding disappeared spontaneously.

The IOL in our case (ATLISA tri 839MP) illustrated the effect of environment on the transparency of hydrophilic acrylic material (25\%) with hydrophobic surface properties in cataract surgery. We could not confirm whether or not acute clouding could alter the mechanical, chemical, or geometric characteristics of the IOL polymer. Long-term changes in the IOL should be investigated in the subsequent follow-ups. The appropriate temperature should be maintained during the storage and transport of IOLs to avoid transient clouding due to temperature fluctuations. IOLs should be handled carefully by the surgeon and kept at room temperature for some time before implantation to prevent clouding.

\section{Conclusion}

IOL clouding can resolve spontaneously; therefore, the patient should be observed.

\section{Abbreviation}

IOL: Intraocular lens

\section{Acknowledgements}

Not applicable.

\section{Authors' contributions}

Study conceptualization and designing: LSH and ZT; data collection: LC, ZRH, $\mathrm{HN}$, and $\mathrm{CCH}$; interpretation and analysis of data: LSH and ZT; drafting of the manuscript: ZT; critical revision of the manuscript: $\mathrm{LSH}$ and $\mathrm{ZT}$. All authors have read and approved the manuscript.

\section{Funding}

This work was supported by Hunan Natural Science Foundation under the grant number 2017JJ2001. The role of the funding was in the collection and analysis of data and in writing the manuscript.

\section{Availability of data and materials}

The datasets from the current study can be obtained on request from the corresponding author.

\section{Ethics approval and consent to participate}

The study was approved by the Ethics Committee of the Aier School of Ophthalmology, Central South University.

\section{Consent for publication}

Written consent for publication of this case report and the accompanying images were obtained from the patient. Copy of the written consent is available for review by the Editor of this journal.

\section{Competing interests}

The authors declare that they have no competing interests.

\section{Author details}

'Department of Ophthalmology, Aier School of Ophthalmology, Central South University, 932 South LushanYuelu District, Changsha 410083, People's Republic of China. ${ }^{2}$ The First Affiliated Hospital of Shantou University Medical

College, Shantou 515041, Guangdong, China. ${ }^{3}$ Department of

Ophthalmology, Beijing Aier-Intech Eye Hospital, NO.12 Panjiayuan

Nanlichaoyang District, Beijing 100021, People's Republic of China.

Received: 18 June 2019 Accepted: 30 September 2019

Published online: 17 October 2019

\section{References}

1. Tyagi P, Shah N, Jabir M. Intraoperative clouding of a posterior chamber intraocular lens. Int Ophthalmol. 2011;31:483-4.

2. Gauthier JH, Pohl PI. A general framework for modeling growth and division of mammalian cells. BMC Syst Biol. 2011;5:3.

3. Kim DJ, Chuck RS, Lee JK, Park CY. Reversible opacification of hydrophobic acrylic intraocular lens- two cases report. BMC Ophthalmol. 2017;17:111.

4. Mojzis P, Studeny P, Werner L, Pinero DP. Late opacification of a hydrophilic acrylic intraocular lens in Europe. Eur J Ophthalmol. 2016;26:e24-6.

5. Dhoot DS, Flaxel CJ. Early opacification and subsequent clearing of a MemoryLens intraocular lens. J Cataract Refract Surg. 2007:33:743-5.

6. Liu Q, Zhang S, Wang X, Cao W, Jia Y. Acute clouding of trifocal lens during implantation: a case report. BMC Ophthalmol. 2017;17:242.

7. Toto L, Calienno R, Curcio C, Mattei PA, Mastropasqua A, Lanzini M, et al. Induced inflammation and apoptosis in femtosecond laser-assisted capsulotomies and manual capsulorhexes: an immunohistochemical study. J Refract Surg. 2015;31:290-4.

8. Hao S, Zhang H. Late postoperative opacification of the hydrophobic acrylic intraocular lens in both eyes. Eye Sci. 2012;27:158-60.

9. Katsimpris JM, Theoulakis PE, Kouzi-Koliakos K, Pavlidou E, Petropoulos IK, Koliakos G, et al. Late postoperative opacification of hydrogel intraocular lenses: analysis of 13 explanted lenses. Klin Monbl Augenheilke. 2009;226: 264-71.

10. Helvaci S. Acute opacification of hydrophobic acrylic intraocular lens during implantation: result of temperature variation. Arq Bras Oftalmol. 2015;78:267.

\section{Publisher's Note}

Springer Nature remains neutral with regard to jurisdictional claims in published maps and institutional affiliations.
Ready to submit your research? Choose BMC and benefit from:
- fast, convenient online submission
- thorough peer review by experienced researchers in your field
- rapid publication on acceptance
- support for research data, including large and complex data types
- gold Open Access which fosters wider collaboration and increased citations
- maximum visibility for your research: over $100 \mathrm{M}$ website views per year
At $\mathrm{BMC}$, research is always in progress.
Learn more biomedcentral.com/submissions 